\title{
Web-Based Geospatial Tools to Address Hazard Mitigation, Natural Resource Management, and Other Societal Issues
}

Federal, State, and local government agencies in the United States face a broad range of issues on a daily basis. Among these are natural hazard mitigation, homeland security, emergency response, economic and community development, water supply, and health and safety services. The U.S. Geological Survey (USGS) helps decision makers address these issues by providing natural hazard assessments, information on energy, mineral, water and biological resources, maps, and other geospatial information.

Increasingly, decision makers at all levels are challenged not by the lack of information, but by the absence of effective tools to synthesize the large volume of data available, and to utilize the data to frame policy options in a straightforward and understandable manner. While geographic information system (GIS) technology has been widely applied to this end, systems with the necessary analytical power have been usable only by trained operators. The USGS is addressing the need for more accessible, manageable data tools by developing a suite of Web-based geospatial applications that will incorporate USGS and cooperating partner data into the decision making process for a variety of critical issues. Examples of Web-based geospatial tools being used to address societal issues follow.

\section{Mapping, Monitoring, and Analysis of Environmental Mercury}

Mercury in our environment - air, water, soil, and especially our food-poses significant hazards to human health, particularly for developing fetuses and young children. Because of the importance of this issue and the length of time it has been studied, large and complex data sets of mercury concentrations in various media and associated ancillary data have been generated by many Federal, State, Tribal, and local agencies. To facilitate the efficient and effective use of these data in managing and mitigating human and wildlife exposure to mercury, the U.S. Geological Survey and the National
Institute of Environmental Health Sciences have developed a Web site for visualizing and studying the distribution of mercury. The Environmental Mercury Mapping, Modeling, and Analysis (EMMMA) Web site is designed to support environmental and health researchers, as well as land and resource managers, by providing useful data, map products, and Web-based tools (Hearn and others, 2006; http://emmma.usgs.gor. Components of EMMMA include:

- Online mapping tools, maps, imagery, and other thematic data used to display and analyze mercury data and to print maps (fig. 1). USGS mapping data provide a nationwide geographic reference composed of aerial photographs, satellite imagery, and geospatial data for land cover, elevation, hydrology, transportation, and geographic names. These data provide a useful geographic context for the mercury data displayed on top of them.

- An online model to describe mercury in fish tissue, which standardizes the

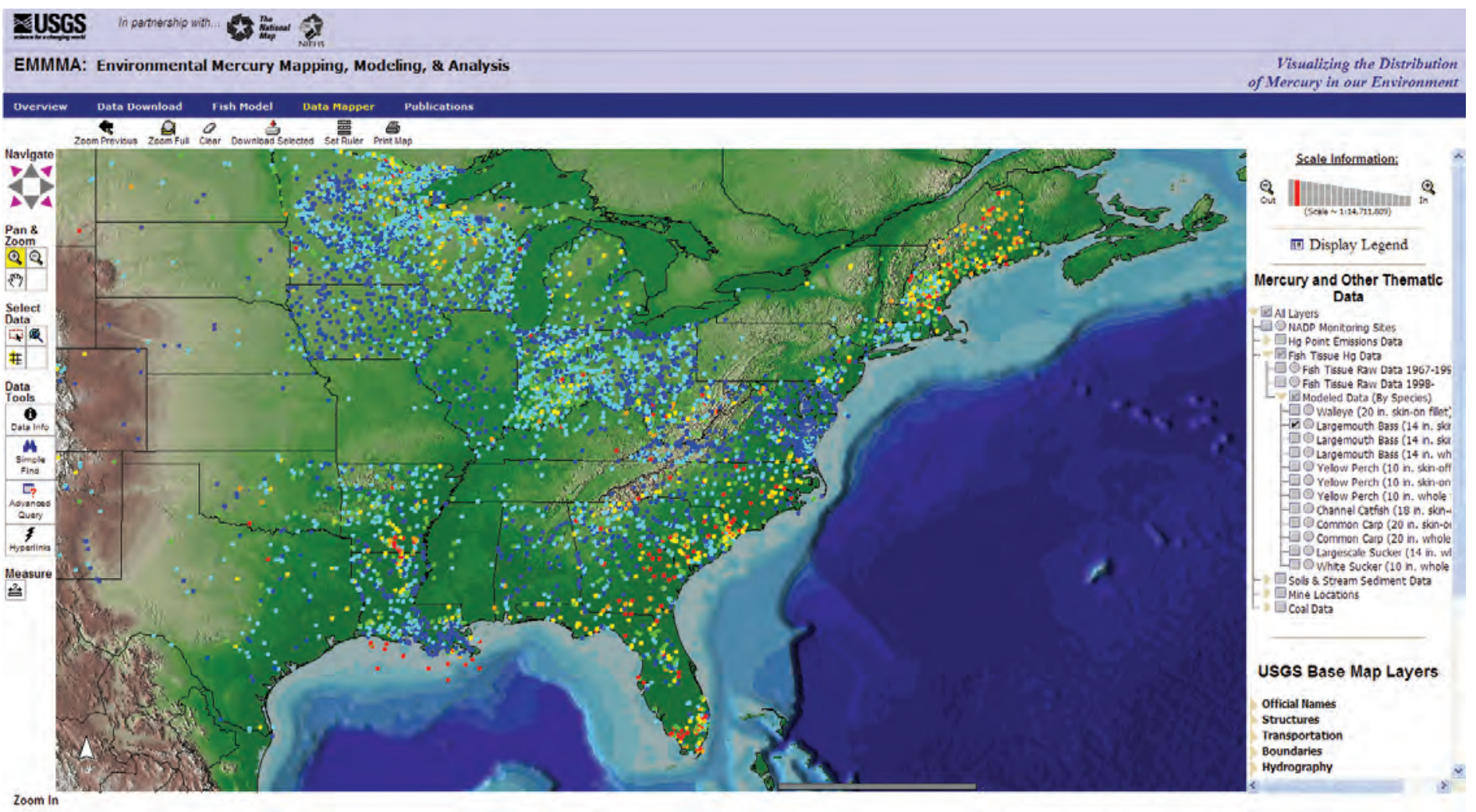

Figure 1. EMMMA's Data Mapper allows users to navigate to and download data from selected locations, and also overlay these data on top of topographic maps, satellite imagery, and aerial photographs. 
concentration of mercury in fish to enable normalized comparisons among different species, individuals of different lengths, and samples of different types. The National Descriptive Model for Mercury in Fish Tissue (NDMMFT) is applied to a comprehensive national compilation of fish-tissue data to detect spatial and temporal trends in mercury concentrations that would otherwise be obscured (Wente, 2004). Modeled data from EMMMA can aid researchers in spotting significant trends in the environment, and also can be used by State agencies to develop more comprehensive and cost-effective fish consumption advisories (fig. 2).

\section{The Land Cover Analysis Tool}

USGS's National Land Cover Dataset (NLCD) is used widely by scientists and land managers to assess changes in land cover that affect water quality, wildlife habitat, human and animal population distribution, carbon storage related to global climate change, and other important environmental, ecological, and societal examples. The Land Cover Analysis Tool (LCAT) is a Web-based tool kit that allows users to quickly locate, display, and download NLCD data, including the recently developed NLCD Change Product, which displays changes in land cover between 1992 and 2001 (http://lcat.usgs.gov).

LCAT allows users to clip, display, and download NLCD data using a variety

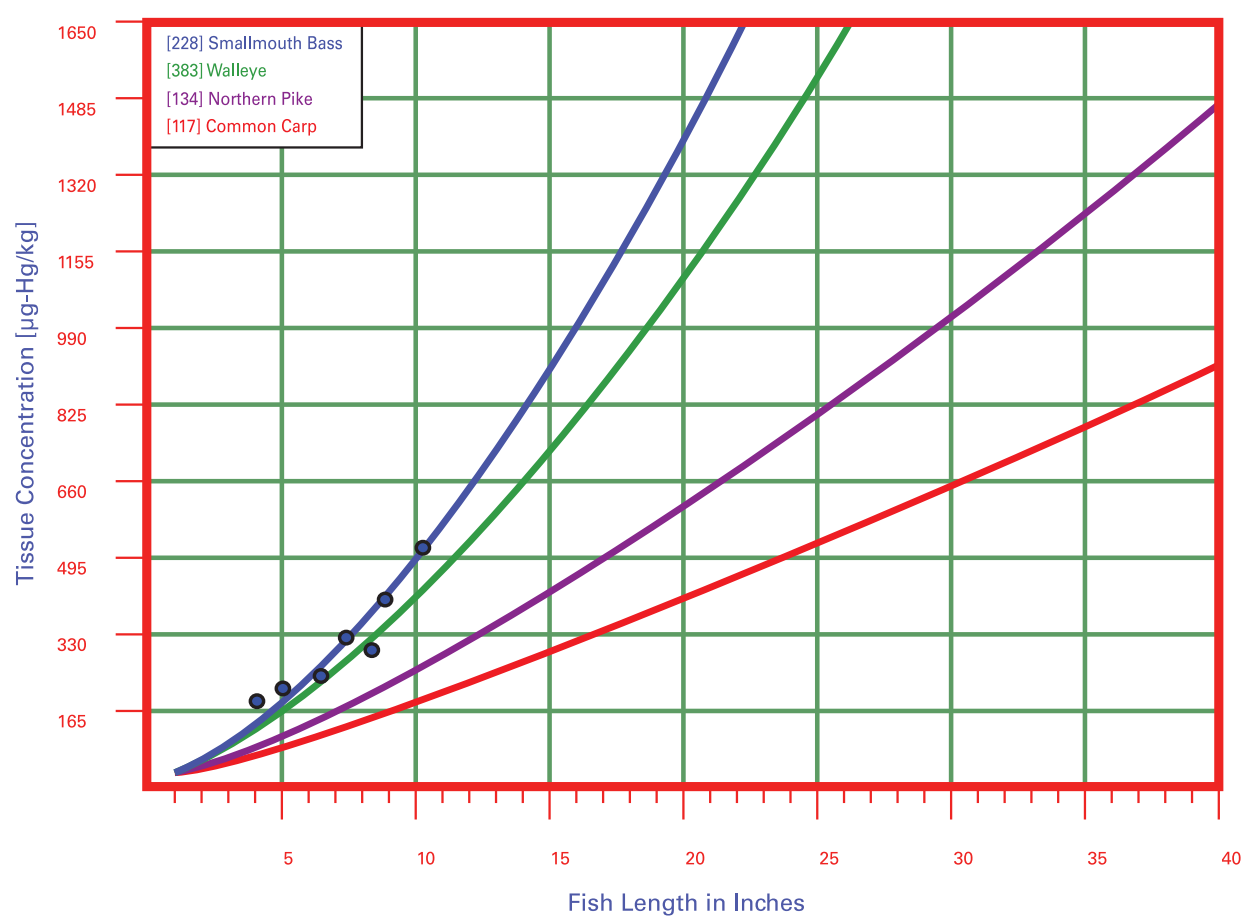

Figure 2. This graph shows a mercury versus fish-length curve fitted by the NDMMFT using mercury data for smallmouth bass (dark blue curve) from a U.S. lake. Using this curve the model can generate curves for other locally occurring species of fish (walleye, northern pike, and carp are shown here) and predict expected mercury content for a given length.

of polygons, including State, county, city, and watershed boundaries; and uploaded GIS shapefiles, including polygons defined onscreen by the user. Additional features include the ability to display individual land cover classes on top of user-selected maps or imagery and the ability to generate and print

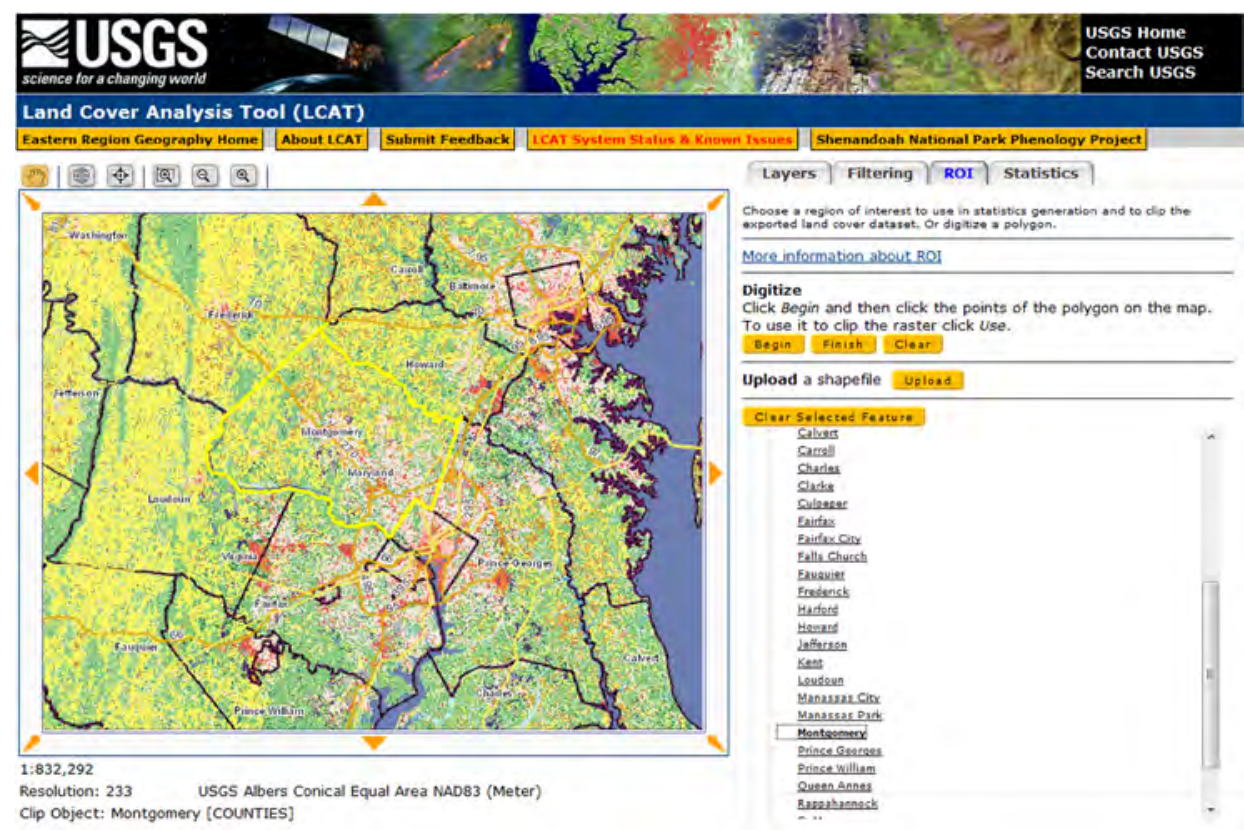

Figure 3. LCAT enables users to rapidly calculate and download various land cover data statistics for a variety of user-defined areas. This figure shows $A$, the results of calculating the 2001 NLCD for Montgomery County, Md.; and B, a graphical representation in the form of a pie diagram and the data table. LCAT requires no special knowledge or software; this calculation was completed in less than 5 seconds.

reports detailing the land cover composition within selected areas. User-selected change pairs (for example, forest to urban) can also be displayed on top of satellite imagery to provide context for areas of change. An example of the type of analysis provided by LCAT is shown in figure 3.
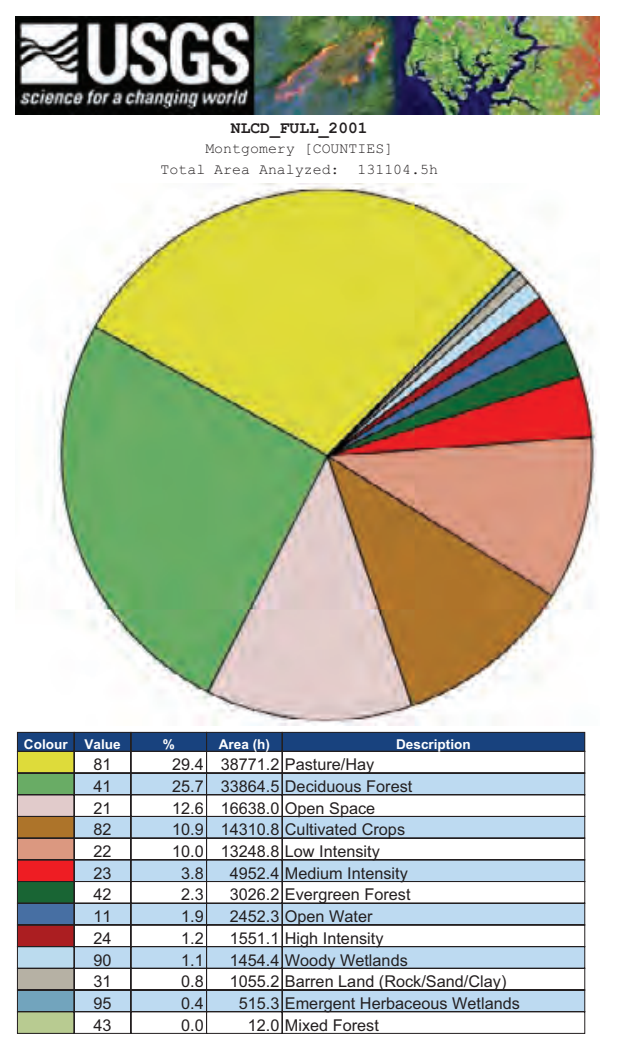


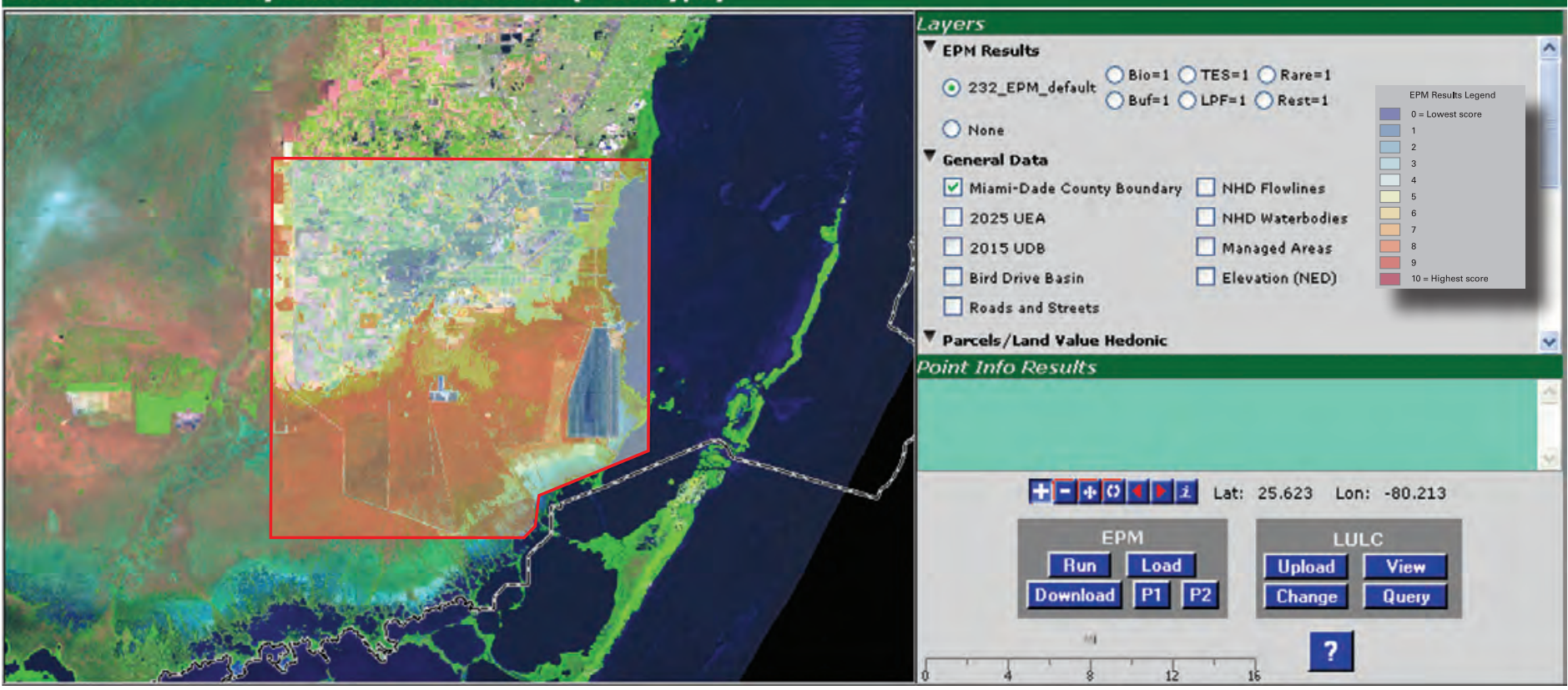

Figure 4. The Ecosystem Portfolio Model allows users to quickly develop suitability maps drawn from elected ecological and other physical data. The red bordered rectangle above shows the extent of an area between the Everglades and Biscayne National Parks that was analyzed for relative suitability. Biodiversity, ecosystem restoration potential, and low landscape fragmentation metrics were chosen as priorities.

\section{The South Florida Ecosystem Portfolio Model}

Intense pressures for development of the land outside of the Urban Development Boundary in Miami-Dade County, Florida, threaten to impact both the Everglades and Biscayne National Parks. In response, the U.S. Geological Survey, in cooperation with the National Park Service and the Wharton School of Economics, has developed a prototype for a Web-enabled geospatial information tool - the South Florida Ecosystem Portfolio Model, or EPM. The EPM allows users to evaluate hypothetical future land use and land cover patterns in terms of habitat availability, indicators of ecological health, water quality criteria, land price changes, and quality of life indicators. The criteria and indicators are chosen to be sensitive to land use and land cover relevant to decision makers and stakeholders, and indicative of future trends. Users may assign weights to these criteria to reflect their views regarding their relative importance. An example of ecological criteria is shown in figure 4 , along with the evaluation results. The EPM project uses contributions from conservation ecology, landscape ecology, decision science, real estate economics, ecological economics, urban planning, GIS analysis, and Web technologies. In the next phase, the Web-based EPM will be extended to other areas of South Florida facing development pressure in natural and agricultural areas. This project will contribute to improved public understanding and awareness of the complex ecological, environmental, and socioeconomic issues involved in land use decisions in southeast Florida, and also offers a useful approach for other areas in the United States where there are competing visions for land use.

\section{Application of the Land Use Portfolio Model to Seismic Hazard Mitigation in Memphis, Tennessee}

The City of Memphis and surrounding Shelby County lie within the New Madrid Seismic Zone, which extends from northeast Arkansas through southeast Missouri and western Tennessee, and western Kentucky to southern Illinois. Historically, Shelby County has been the site of some of the largest earthquakes in North America. Earthquakes with estimated magnitudes between 7.5 and 8.0 occurred in this area between 1811 and 1812 (Gomberg and Schweig, 2003). The City of Memphis and portions of Shelby County have been mapped by the USGS to assess the level of seismic hazard (fig. 5; http:/learthquake.usgs.gov/regional ceus/index.php). Shelby County was chosen as an area to evaluate the Land Use Portfolio Model (LUPM), a modeling, mapping, and risk communication tool that can assist public agencies and communities in understanding and reducing their natural-hazards vulnerability Lttp://geography.wr.usgs.gov/science

The LUPM builds upon financialportfolio theory, a method for evaluating alternative investment choices based on the estimated distribution of risk and return from different investment options. The LUPM been has developed into an interactive, GIS-based decision support system that stakeholders can use to select locations in which to invest a hazard mitigation budget, evaluate metrics such as the mean and variance of community wealth, and compare and rank policies. The model is unique in that it allows users to think through various levels of risk tolerance and hazard acceptability and to compare the cost effectiveness of alternative policies.

Initial results from LUPM runs demonstrate the effect of earthquake probability estimates, planning horizons, and the cost of mitigation estimates on hazard mitigation investments (Bernknopf and others, 2007). Also, the desktop version of LUPM is being modified to create a Web-based version, which will provide managers and policy makers with a simplified interface to better understand how the model works and how it can benefit the analysis of hazard mitigation policies. 


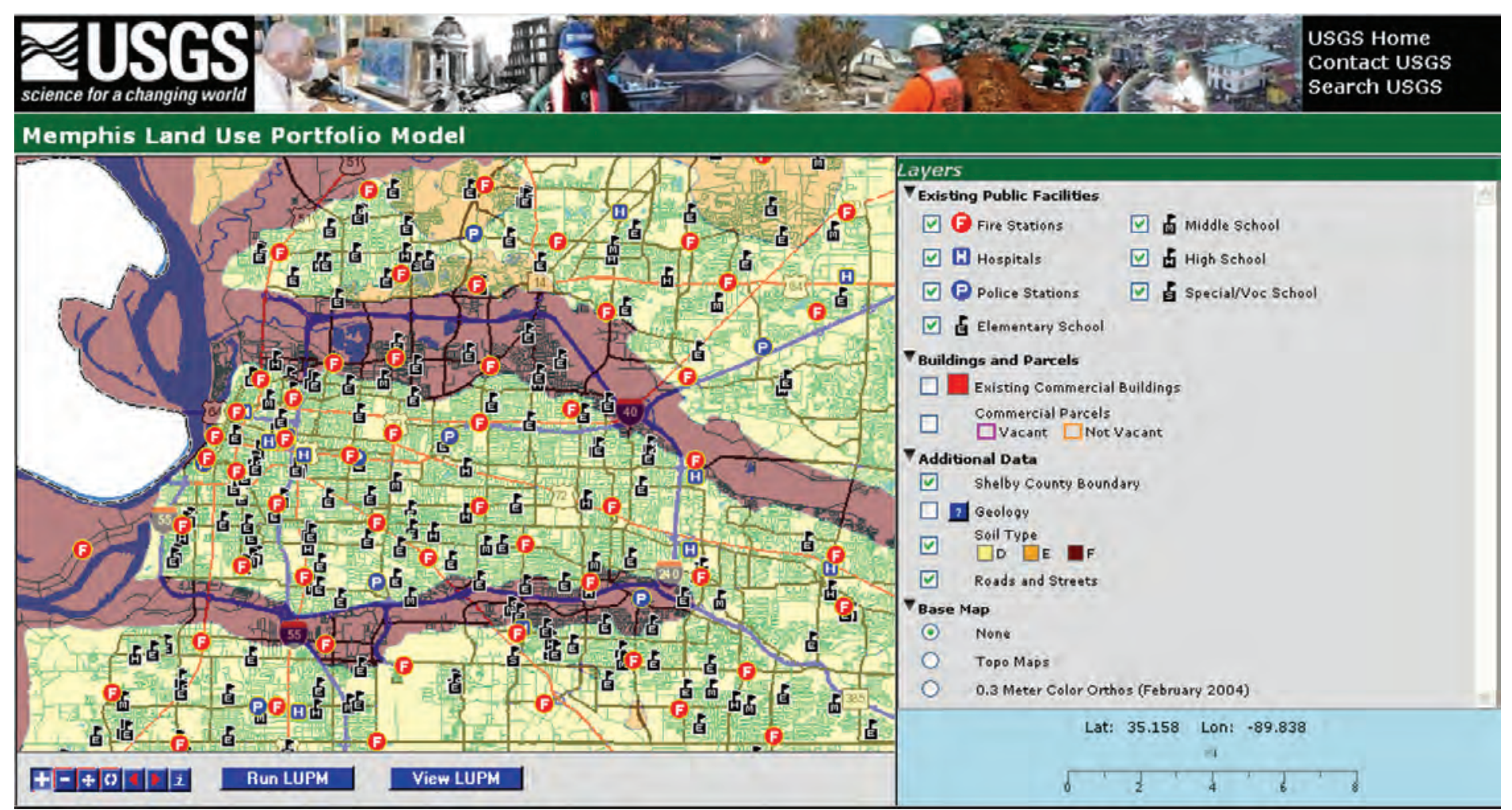

Figure 5. One application of the LUPM in Memphis is to provide a planning tool for municipal authorities responsible for schools, police stations, fire stations, and other public buildings. The LUPM will allow managers to test various scenarios for the mitigation of seismic risk to these assets and evaluate mitigation costs required to lower the risk from specified seismic events.

\section{References Cited}

Bernknopf, R.L., Hearn, P.P., Wein, A.M., and Strong, David, 2007, The effect of scientific and socioeconomic uncertainty on a natural hazards policy choice, in International Congress on Modeling and SimulationMODSIM07, December 2007, Christchurch, New Zealand: Christchurch, Modeling and Simulation Society of Australia and New Zealand Proceedings, p. 1702-1708.
Gomberg, J., and Schweig, E., 2003, Earthquake hazard in the heart of the homeland: U.S. Geological Survey Fact Sheet 131-02, 4 p. (Also available at http://pubs.usgs.gov/fs/fs-131-021.)

Hearn, P.P., Wente, S.P., Donato, D.I., and Aguinaldo, J.J., 2006, EMMMA-A Web-based system for environmental mercury mapping, modeling, and analysis: U.S. Geological Survey Open-File Report 2006-1086, 13 p. (Also available at http://erg.usgs.gov/isb/pubs ofrs/2006-1086/ofr2006-1086.pd). )

Wente, S.P., 2004, A statistical model and national data set for partitioning fishtissue mercury concentration variation between spatiotemporal and sample characteristic effects: U.S. Geological Survey Scientific Investigations Report 2004-5199, 15 p. (Also available at http://pubs.usgs.gov/sir/2004/5199 pdf/2004-5199.pdf)

Author-Paul P. Hearn, Jr.

\section{For more information, please contact}

\section{EMMMA, LCAT, and the Memphis LUPM}

Paul P. Hearn, Jr.

U.S. Geological Survey

Eastern Geographic Science Center

MS 521, National Center

12201 Sunrise Valley Drive

Reston, VA 20192

Phone: (703) 648-6287

E-mail:phearn@usgs.gov
South Florida EPM

Bill Labiosa

U.S. Geological Survey

Western Geographic Science Center

MS 531, 345 Middlefield Road

Menlo Park, CA 94025

Phone: (650) 329-4279

E-mail:blabiosa@usgs.gov 